\title{
On the symmetry of phosphorous doped ZnSe
}

\author{
N SANKAR ${ }^{\dagger}$ and K RAMACHANDRAN* \\ Department of Theoretical Physics, Madurai Kamaraj University, Maduri 625 021, India \\ ${ }^{\dagger}$ Department of Physics, Yadava College, Madurai 625 014, India
}

\begin{abstract}
The site symmetry of $P$ doped $\mathrm{ZnSe}$ is analysed in detail here, as the recent experiments suggest two possible symmetries $T_{\mathrm{d}}$ and $C_{3 \mathrm{v}}$. The reduction to $C_{3 \mathrm{~V}}$ is attributed to the presence of natural impurity, Ga. Our calculations based on molecular model and Green's functions suggest that the symmetry $C_{3 \mathrm{v}}$ is possible with ZnSe : P when Jahn Teller distortion of about $\sim 0.2 \AA$ (towards one of $\mathrm{Zn}$ atom) is assumed. This has been supported by other experiments.
\end{abstract}

Keywords. ZnSe; localized vibrational modes; $T_{\mathrm{d}}$ and $C_{3 \mathrm{~V}}$ symmetries; Jahn Teller distortion; Green's function; molecular model.

\section{Introduction}

The wide gap semiconductor, $\mathrm{ZnSe}$, is an example of potential applications in optoelectronic devices, such as blue light emitting diodes and blue diode lasers. Using the molecular beam epitaxy method, Hasse et al (1991) have demonstrated that $\mathrm{ZnSe}$ diodes lase in the bluegreen region. In spite of the fabrication of low resistivity $p$-type ZnSe using nitrogen as the dopant, doping still remains complicated. Similarly even though a lot of experimental and theoretical investigations are available in the literature for the defect modes in II-VI systems, the role of phosphorous as a $p$-type dopant in $\mathrm{ZnSe}$ is not fully understood. For low doping, the photoluminescence seems to be due to the recombination of excitons bounding neutral acceptors. The reported experiments (Yao and Okada 1986; Qiu et al 1991) could not exactly predict the nature of symmetry of the shallow acceptors introduced by the doping.

Electron spin resonance (ESR) (Watts et al 1971) and optically detected magnetic resonance (ODMR) (Nicholls and Davies 1979) suggest that phosphorous substitutes selenium site in $\mathrm{ZnSe}$ and acts as a deep acceptor at about $0.7 \mathrm{eV}$. These deep level defects under certain conditions give rise to the Dx centres (Localized vibrational modes (LVMs) for such Dx centres are already observed for GaAs : Si (Wolk et al 1991)).

\section{Symmetry}

The ESR experiments show that $[\mathrm{Pse}]^{0}$ centres do not possess the $T_{\mathrm{d}}$ symmetry, as expected for any simple

\footnotetext{
*Author for correspondence
}

case. Instead, this is predicted to be $C_{3 \mathrm{~V}}$ symmetry (Watts et al 1971). The reduction in the symmetry is ascribed to the Jahn Teller type distortion.

Also this ESR spectra could be bleached by IR radiation with energies $>0.8 \mathrm{eV}$ (Watts et al 1971).

Generally, phosphorous centre is expected to be non magnetic and would be of $T_{\mathrm{d}}$ symmetry in $\mathrm{ZnSe}$. Then, only a Jahn Teller type distortion can lead to $C_{3 \mathrm{~V}}$ symmetry as a result of three-fold degeneracy in $T_{\mathrm{d}}$ surroundings. So, it is understood that photocreation of the neutral acceptors involves a change in the symmetry. Alternatively, another model avoids the Jahn Teller distortion where $C_{3 \mathrm{~V}}$ symmetry is possible with nearby impurity or defect, irrespective of the charge state, i.e. the non magnetic state would have $C_{3 \mathrm{~V}}$ symmetry, rather than $T_{\mathrm{d}}$ as expected.

To distinguish between these models on the nature of symmetry of $\mathrm{P}_{\mathrm{Se}}$ in ZnSe, Raman spectrum for ZnSe : P,Ga is observed by Nakano et al (1992) in the range $180-420 \mathrm{~cm}^{-1}$. There are two stronger modes at 210 and $255 \mathrm{~cm}^{-1}$ with weaker modes at 220 and $375 \mathrm{~cm}^{-1}$. From the measurements of phonons on host ZnSe (Taylor 1967), Nakano et al attributed these modes, 210 and $255 \mathrm{~cm}^{-1}$, to correspond to TO and LO phonon modes of $\mathrm{ZnSe}$. The two weaker modes do not appear in a variety of $\mathrm{ZnSe}$ specimens whether for undoped or doped with elements other than phosphorous and gallium.

The polarization behaviour is also discussed by Nakano et al (1992), which suggests that the $375 \mathrm{~cm}^{-1}$ correspond to a simple substitutional centre, from $T_{\mathrm{d}}$ symmetry whereas $220 \mathrm{~cm}^{-1}$ corresponds to $A_{1}$ mode of either $T_{\mathrm{d}}$ or $C_{3 \mathrm{~V}}$ and could not be distinguished.

Because of this interesting behaviour of $\mathrm{ZnSe}: \mathrm{P}$, a detailed theoretical investigation is attempted here, to identify the nature of symmetry. 


\section{Localized vibrational modes due to $p$ doped $\mathrm{ZnSe}$}

The LVMs are calculated extensively by two approaches: (i) molecular model and (ii) green's function technique.

(i) Molecular model: The well established technique to workout the defect modes is molecular model, where a single molecule will be considered. In brief, the dynamical matrix will be constructed from the long range and short range interactions.

On diagonalization of this matrix, one can get the normal modes and the localized vibrational mode (LVM) can be identified from the eigen displacement of the defect atom.

ZnSe possesses $T_{\mathrm{d}}$ symmetry as represented in figure 1, with selenium at the centre. When this is doped with phosphorous, it substitutes $\mathrm{Se}$ atom and still retains the $T_{\mathrm{d}}$ symmetry, to start with when any other deformation is not considered.

The dynamical matrix, which is $15 \times 15$ (in terms of $\left.\mathrm{e}^{2} / \mathrm{V}\right)$, is constructed as with the long and short range interactions taking only first neighbours. The short range part of the dynamical matrix is given here for continuity. and A and B are Kellerman's constants, for the corresponding system.

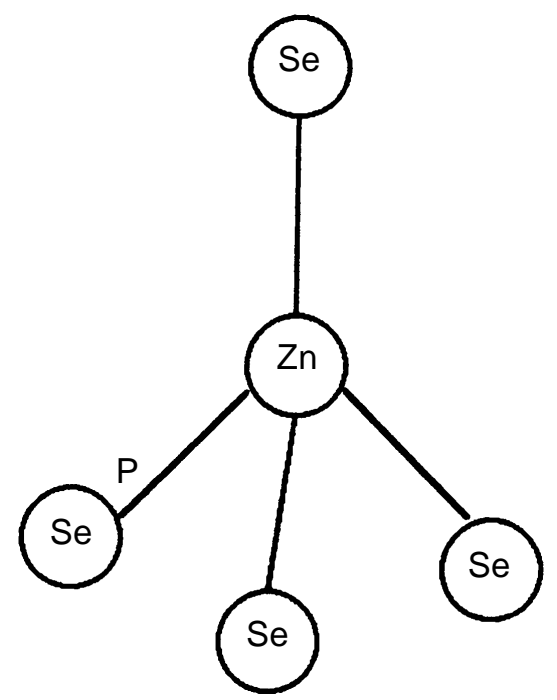

Figure 1. Molecular structure for $T_{\mathrm{d}}$ symmetry.

\begin{tabular}{|c|c|c|c|c|c|c|c|c|c|c|c|c|c|c|c|}
\hline & 1 & 2 & 3 & 4 & 5 & 6 & 7 & 8 & 9 & 10 & 11 & 12 & 13 & 14 & 15 \\
\hline 1 & A & B & B & $\mathrm{C}$ & D & $\mathrm{D}$ & $\mathrm{E}$ & F & $-F$ & $\mathrm{E}$ & $-F$ & $\mathrm{~F}$ & E & $-F$ & $-F$ \\
\hline 2 & & A & B & $\mathrm{D}$ & $\mathrm{C}$ & D & $\mathrm{F}$ & $\mathrm{E}$ & $-F$ & $-F$ & E & $-F$ & $-F$ & E & F \\
\hline 3 & & & A & D & D & $\mathrm{C}$ & $-F$ & $-\bar{F}$ & $\mathrm{E}$ & F & $-F$ & $\mathrm{E}$ & $-F$ & $\mathrm{~F}$ & E \\
\hline 4 & & & & $\mathrm{G}$ & $\mathrm{H}$ & $\mathrm{H}$ & & & & & & & & & \\
\hline 5 & & & & & $\mathrm{G}$ & $\mathrm{H}$ & & & & & & 0 & & & \\
\hline 6 & & & & & & $\mathrm{G}$ & & & & & & & & & \\
\hline 7 & & & & & & & I & $\mathrm{J}$ & $-\mathrm{J}$ & & & & & & \\
\hline 8 & & & & & & & & I & $-\mathbf{J}$ & & & 0 & & & \\
\hline 9 & & & & & & & & & I & & & & & & \\
\hline 10 & & & & & & & & & & I & $-\mathbf{J}$ & $\mathrm{J}$ & & & \\
\hline 11 & & & & & & & & & & & I & $-\mathrm{J}$ & & 0 & \\
\hline 12 & & & & & & & & & & & & I & & & \\
\hline 13 & & & & & & & & & & & & & I & $-\mathrm{J}$ & $-\mathbf{J}$ \\
\hline 14 & & & & & & & & & & & & & & I & $\mathrm{J}$ \\
\hline 15 & & & & & & & & & & & & & & & I \\
\hline
\end{tabular}

Only upper half of the matrix is given, as it is symmetric.

where

$$
\begin{aligned}
& \mathrm{A}=\left(\mathrm{A}_{1}+3 \mathrm{~A}_{2}\right) / \mathrm{M}_{\mathrm{P}} \\
& \mathrm{C}=-\mathrm{A}_{1} / \sqrt{\mathrm{M}_{\mathrm{Zn}} \mathrm{M}_{\mathrm{P}}} \\
& \mathrm{E}=-\mathrm{A}_{2} / \sqrt{ } \mathrm{M}_{\mathrm{Zn}} \mathrm{M}_{\mathrm{P}} \\
& \mathrm{G}=\left(\mathrm{A}_{1}+3 \mathrm{~A}_{3}\right) / \mathrm{M}_{\mathrm{Zn}} \\
& \mathrm{I}=\left(\mathrm{A}_{2}+3 \mathrm{~A}_{4}\right) / \mathrm{M}_{\mathrm{Zn}} \\
& \mathrm{A}_{1}=\left(\mathrm{A}_{\mathrm{ZnP}}+2 \mathrm{~B}_{\mathrm{ZnP}}\right) / 6 \\
& \mathrm{~A}_{2}=\left(\mathrm{A}_{\mathrm{ZnP}}+2 \mathrm{~B}_{\mathrm{ZnP}}\right) / 6 \\
& \mathrm{~A}_{3}=\left(\mathrm{A}_{\mathrm{ZnSe}}+2 \mathrm{~B}_{\mathrm{ZnSe}}\right) / 6 \\
& \mathrm{~A}_{4}=\left(\mathrm{A}_{\mathrm{ZnSe}}+2 \mathrm{~B}_{\mathrm{ZnSe}}\right) / 6
\end{aligned}
$$

The force constants, $\mathrm{A}_{\mathrm{ZnSe}}$ and $\mathrm{B}_{\mathrm{ZnSe}}$, are worked out to construct the above dynamical matrix, from the available experimental data on elastic constants (Kusakov et al 1973) and phonon frequencies (Matsuo et al 1984) of $\mathrm{ZnSe}$ based on a rigid ion model, and are given in table 1 for $\mathrm{Zn}-\mathrm{Se}$ bond. Such data for $\mathrm{ZnP}$ or $\mathrm{ZnSe}: \mathrm{P}$ are not immediately available and so an approximate method is followed to work out the force constants of $\mathrm{Zn}-\mathrm{P}$. That is, $A_{\mathrm{Zn}-\mathrm{P}}$ is worked from the Debye temperature (Sheleg and Kutas 1981). The same is compared with the host force constant of zinc diphosphite for which the data is available. There is a correspondence between the two (But only the previous value is considered for the present 
Table 1. Constants used to evaluate LVMs for ZnSe : $\mathrm{P}$ in molecular model.

\begin{tabular}{|c|c|c|c|c|c|c|c|}
\hline \multirow[b]{2}{*}{$\begin{array}{l}\text { Cell constant } \\
a(\AA)\end{array}$} & \multicolumn{3}{|c|}{ Elastic constants in dynes $\left[\mathrm{cm}^{2}\left(\times 10^{11}\right)\right]$} & \multicolumn{4}{|c|}{ Force constants $\left(\mathrm{e}^{2} / \mathrm{V}\right)$} \\
\hline & $\begin{array}{r}\text { Elastic } \\
\qquad C_{11}\end{array}$ & $\begin{array}{l}C_{12} \\
C_{1}\end{array}$ & $\begin{array}{c}\left.\left(\times 10^{11}\right)\right] \\
C_{44}\end{array}$ & $\mathrm{~A}_{\mathrm{Zn}-\mathrm{Se}}$ & $\mathrm{B}_{\mathrm{Zn}-\mathrm{Se}}$ & $\mathrm{A}_{\mathrm{Zn}-\mathrm{P}}$ & $\mathrm{B}_{\mathrm{Zn}-\mathrm{P}}$ \\
\hline $5 \cdot 6676$ & 8.95 & $5 \cdot 39$ & 3.98 & $75 \cdot 05$ & $-1 \cdot 15$ & $45 \cdot 66$ & -0.699 \\
\hline
\end{tabular}

Table 2. Scattering symmetries of phonons.

\begin{tabular}{lll}
\hline & \multicolumn{2}{c}{ Representation } \\
\cline { 2 - 3 } Coordinates & \multicolumn{1}{c}{ For $T_{\mathrm{d}}$} & For $C_{3 \mathrm{~V}}$ \\
\hline$z(y, y) \bar{z}$ & $\mathrm{~A}_{1}, \mathrm{E}$ & $\mathrm{A}_{1}, \mathrm{E}$ \\
$z(y, x) \bar{z}$ & $T_{2}$ & $\mathrm{E}$ \\
$z(x, y) \bar{z}$ & $T_{2}$ & $\mathrm{E}$ \\
$z(x, x) \bar{z}$ & $\mathrm{~A}_{1}, \mathrm{E}, T_{2}$ & $\mathrm{~A}_{1}, \mathrm{E}$ \\
$z\left(x^{\prime}, x^{\prime}\right) \bar{z}$ & $\mathrm{~A}_{1}, T_{2}$ & $\mathrm{~A}_{1}, \mathrm{E}$ \\
$z\left(x^{\prime}, y^{\prime}\right) \bar{z}$ & $\mathrm{E}, T_{2}$ & $\mathrm{~A}_{1}, \mathrm{E}$ \\
\hline
\end{tabular}

calculations). This is what is represented in table 1 for $\mathrm{A}_{\mathrm{Zn}-\mathrm{P}}$.

With these parameters, the defect modes are worked for the $T_{\mathrm{d}}$ symmetry, by diagonalizing the dynamical matrix and looking at the eigen frequencies and eigen displacements. These values are given in table 3 , along with the Raman measurements for LVMs. We find that there are two modes $371 \mathrm{~cm}^{-1}$ and $221 \mathrm{~cm}^{-1}$ for LVMs here (the displacement of the defect atom will fall off rapidly, exponentially, as distance goes about the defect atom for fixing an LVM). When the displacements corresponding to the 15 modes are analysed by the geometry, these modes correspond to $T_{2}$ and $A_{1}$ representation of $T_{\mathrm{d}}$ symmetry. This is explicitly shown here. When Nakano et al (1992) studied the defect modes the symmetry of the displacements were given for both $T_{\mathrm{d}}$ and $C_{3 \mathrm{~V}}$, which is displayed here in table 2 for comparison with our results. The eigen displacements which we obtained from our calculations are given in table 3 . Tables 2 and 3 show that $371 \mathrm{~cm}^{-1}$ and $221 \mathrm{~cm}^{-1}$ correspond to $T_{2}$ and $A_{1}$ representations of $T_{\mathrm{d}}$ symmetry. When we compare with the $C_{3 \mathrm{~V}}$ symmetry it is found that this $221 \mathrm{~cm}^{-1}$ belongs to this symmetry.

Since $221 \mathrm{~cm}^{-1}$ appears to be both in $T_{\mathrm{d}}$ and $C_{3 \mathrm{~V}}$ symmetries, it is attempted to see how this $C_{3 \mathrm{~V}}$ is possible when only $\mathrm{P}$ is substituted in $\mathrm{ZnSe}$. The most trivial case is that there should be some other impurities present in ZnSe which brings down the symmetry, which will also be seen. When $\mathrm{P}$ is substituted at $\mathrm{Se}$ site, there is a change in force constant in $\mathrm{Zn}-\mathrm{P}$ bond as there should be a distortion (Kwak et al 1994) like Jahn Teller type (JT).

This should be checked for $C_{3 \mathrm{~V}}$ symmetry as Nakano et al (1992) claim that $C_{3 \mathrm{~V}}$ and $T_{\mathrm{d}}$ could not be distinguished for $220 \mathrm{~cm}^{-1}$.

Any distortion in the bond will be reflected in the force constant which is obtained as follows.
When there is a Jahn Teller (JT) type distortion it is found (Kwak et al 1994) that $\mathrm{P}$ atom moves about $0.2 \AA$ toward one of the four neighbouring Se atoms, lowering the symmetry of the defect from $T_{\mathrm{d}}$ to $C_{3 \mathrm{~V}}$. Since, it is reported that the relaxation is about $0 \cdot 2 \AA$, any other computations are not carried out here to work out the relaxed coordinate of the atoms in the molecule. It is attempted to find the change in force constant, due to this relaxation, a Lennard Jones type potential is assumed for interaction between the neighbours. So in $\mathrm{ZnSe}$ the force constant for $\mathrm{Zn}-\mathrm{Se}$ is worked out, by taking the distance between $\mathrm{Zn}$ and $\mathrm{Se}$ as $2.8338 \AA$ in unrelaxed situation and when P moves by $0 \cdot 17 \AA$, the new force constant can be worked out by changing the value of the distance between $\mathrm{P}(\mathrm{Zn})$ and $\mathrm{Se}$ as $3.0038 \AA$. The difference between these force constants is attributed to the contribution from JT distortion. The modified force constant $\mathrm{A}_{\mathrm{Zn}-\mathrm{P}}$ and $\mathrm{B}_{\mathrm{Zn}-\mathrm{P}}$ are given in table 4 .

As usual, with these new set of parameters the dynamical matrix is constructed and solved for LVMs.

The LVMs are properly picked out from the eigen displacements in the usual way. The results are given in table 4.

Now, when this is compared with the symmetry of the eigen displacements it is seen that $220 \mathrm{~cm}^{-1}$ belongs to $C_{3 \mathrm{~V}}$ symmetry. This is an interesting result, as a JT type distortion naturally will affect the symmetry of the system. Kwak et al (1994) recently suggested by some other experiments that this JT distortion is dominant in ZnSe.

ZnSe: $P, G a$ : The other possibility is the natural defect. To work out the defect modes corresponding to $C_{3 \mathrm{~V}}$ symmetry, following the findings of Nakano et al (1992) that gallium impurity substitutes one of the $\mathrm{Zn}$ atom in the molecule, is considered as given in figure 2 . The site symmetry is reduced to $C_{3 \mathrm{~V}}$ from $T_{\mathrm{d}}$ in this case. Here when $\mathrm{Ga}$ is substituted at $\mathrm{Zn}$ the new force constant $\mathrm{A}_{\mathrm{Ga}-\mathrm{P}}$ is worked out from the bond length and a Lennard Jones type since $\mathrm{A}_{\mathrm{Ga}-\mathrm{Se}}$ already is available (Jandl et al 1976). The force constant $\mathrm{A}_{\mathrm{Ga}-\mathrm{P}}$ is calculated using phonon frequency and elastic constant. The various force constants used are given in table 5 .

Again the dynamical matrix for this defect pair is constructed and diagonalized for defect modes and they are given in table 6 , along with the experimental values. We obtain the mode $220 \mathrm{~cm}^{-1}$ in this case also, but when we look at the geometry of the displacements, in relation 
Table 3. LVMs calculation for ZnSe : P using molecular model in $T_{\mathrm{d}}$ symmetry.

\begin{tabular}{|c|c|c|c|c|c|c|c|c|}
\hline \multirow[b]{2}{*}{ Sl. no. } & \multirow{2}{*}{$\begin{array}{c}\text { Calculated } \\
\text { LVMs } \\
\left(\mathrm{cm}^{-1}\right)\end{array}$} & \multicolumn{6}{|c|}{ Displacements } & \multirow{2}{*}{$\begin{array}{c}\text { Experimenta } \\
\text { LVMs } \\
\left(\mathrm{cm}^{-1}\right)\end{array}$} \\
\hline & & $x_{1}$ & $y_{1}$ & $z_{1}$ & $x_{2}$ & $y_{2}$ & $z_{2}$ & \\
\hline 1 & 371.23 & 0.46 & 0.46 & 0.46 & $-0 \cdot 31$ & $-0 \cdot 31$ & $-0 \cdot 31$ & 375 \\
\hline 2 & $221 \cdot 58$ & 0.028 & 0.028 & 0.028 & $0 \cdot 21$ & 0.21 & 0.21 & 220 \\
\hline
\end{tabular}

Table 4. Modified force constants and LVMs for $\mathrm{Zn}-\mathrm{Se}: \mathrm{P}$ in molecular model.

\begin{tabular}{|c|c|c|c|c|c|c|c|c|c|}
\hline \multicolumn{2}{|c|}{$\begin{array}{l}\text { Modified force constants } \\
\left(\mathrm{e}^{2} / \mathrm{V}\right)\end{array}$} & \multirow{2}{*}{$\begin{array}{l}\text { Calculated } \\
\text { LVMs } \\
\left(\mathrm{cm}^{-1}\right)\end{array}$} & \multicolumn{6}{|c|}{ Displacements } & \multirow{2}{*}{$\begin{array}{c}\text { Experimenta } \\
\text { LVMs }^{-1} \\
\left(\mathrm{~cm}^{-1}\right)\end{array}$} \\
\hline $\mathrm{A}_{\mathrm{Zn}-\mathrm{P}}$ & $\mathrm{B}_{\mathrm{Zn}-\mathrm{P}}$ & & $x_{1}$ & $y_{1}$ & $z_{1}$ & $x_{2}$ & $y_{2}$ & $z_{2}$ & \\
\hline $12 \cdot 300$ & $0 \cdot 819$ & $\begin{array}{l}223 \\
271\end{array}$ & $\begin{array}{r}0.38 \\
-0.15\end{array}$ & $\begin{array}{r}0.38 \\
-0.15\end{array}$ & $\begin{array}{r}0.38 \\
-0.15\end{array}$ & $\begin{array}{r}-0.39 \\
0.07\end{array}$ & $\begin{array}{r}-0.39 \\
0.07\end{array}$ & $\begin{array}{r}-0.39 \\
0.07\end{array}$ & $\begin{array}{l}220 \\
375\end{array}$ \\
\hline
\end{tabular}

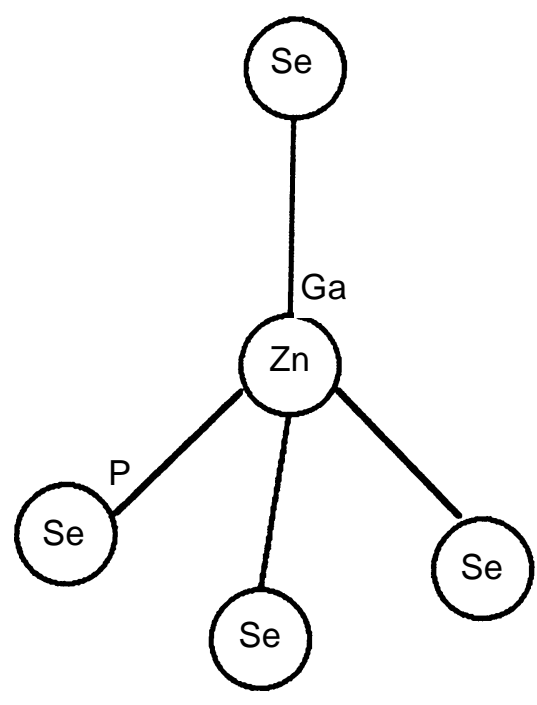

Figure 2. Molecular structure for $C_{3 \mathrm{~V}}$ symmetry.

with $C_{3 \mathrm{~V}}$ symmetry, these modes occur in the $\mathrm{A}_{1}$ representation.

This $220 \mathrm{~cm}^{-1}$ occurs both in $T_{\mathrm{d}}$ and $C_{3 \mathrm{~V}}$ for $\mathrm{A}_{1}$ representation. This indicates that there are two possibilities of $\mathrm{ZnSe}: \mathrm{P}$. It is rather difficult to identify the centre possible for this model, when other natural impurity is not considered.

The above molecular model calculations for $C_{3 \mathrm{~V}}$ symmetry (with $\mathrm{Ga}$ as additional additive impurity) giving $220 \mathrm{~cm}^{-1}$ may not be equally true for any other unidentified impurity. This is the reason why Nakano et al (1992) have observed Raman's spectrum for $\mathrm{ZnSe}: \mathrm{P}, \mathrm{Ga}$.

(ii) Green's function technique: The LVMs are worked out from Green's function technique. The detailed theory is available in Maradudin et al (1971) and so will not be repeated here.

To start with $T_{\mathrm{d}}$ symmetry of $\mathrm{ZnSe}: \mathrm{P}$ is considered. As the perturbation matrix $\delta l$ is $(15 \times 15)$, group theoretical simplification is done, taking the symmetry coordinates for $T_{\mathrm{d}}$ symmetry, which reduces to

$$
\Gamma^{(15)}=\mathrm{A}_{1}+\mathrm{E}+\mathrm{F}_{1}+3 \mathrm{~F}_{2} \text {. }
$$

Similarly, we can construct the Green's functions matrix $(15 \times 15)$ for the host system from

$$
g_{\alpha \beta}\left(\begin{array}{l}
0 l \\
k k^{\prime}
\end{array}\right)=\frac{1}{N} \sum_{q_{j}} \frac{e_{\alpha}\left(k \mid q_{j}\right) e^{*}\left(k^{\prime} \mid q_{j}\right)}{\left(x^{2}-x_{j}^{2}(q)\right)} \cos \left[2 \circlearrowright \bar{q} \cdot \bar{r}\left(\begin{array}{l}
0 l \\
k k^{\prime}
\end{array}\right)\right] .
$$

This is also reduced with the same symmetry coordinates. The localized modes are then calculated from

$$
|I-g \delta l|=0 \text {. }
$$

The $g$ and $\delta l$ matrices for $T_{2}$ representation is given as follows. Block diagonalized form of $g$ and $\delta l$ for isolated substitutional case when the nearest neighbours alone are included.

$$
T_{2}=\left[\begin{array}{ccc}
-32 \mathrm{Y}+16 \mathrm{~B}+4 \mathrm{~A}_{1} & 4[-\mathrm{B}-3 \mathrm{Y}+ & \\
\frac{+8 \mathrm{P}_{1}+4 \mathrm{Q}_{1}}{20} & \frac{\mathrm{A}_{1}+2 \mathrm{P}_{1}+\mathrm{Q}_{1}}{10} & \frac{8\left[-\mathrm{R}_{1}+4 \mathrm{Z}\right]}{12 \cdot 65} \\
& \frac{\mathrm{B}+8 \mathrm{Y}+4 \mathrm{~A}_{1}+}{5} & \frac{-8 \mathrm{R}_{1}+8 \mathrm{Z}}{6 \cdot 32} \\
& \frac{4 \mathrm{P}_{1}+4 \mathrm{Q}_{1}}{5} & \mathrm{~A}_{1}-\mathrm{Q}_{1}-\mathrm{R}_{1}+2 \mathrm{~S}_{1}
\end{array}\right],
$$

$T_{2}$ for $\delta l$ matrix 
Table 5. Constants used to evaluate LVMs for the system $\mathrm{ZnSe}: \mathrm{P}, \mathrm{Ga}$.

\begin{tabular}{cccccccc}
\hline \multicolumn{7}{c}{ Force constants $\left(\mathrm{e}^{2} / \mathrm{V}\right)$} \\
$\mathrm{A}_{\mathrm{Zn}-\mathrm{Se}}$ & $\mathrm{B}_{\mathrm{Zn}-\mathrm{Se}}$ & $\mathrm{A}_{\mathrm{Zn}-\mathrm{P}}$ & $\mathrm{B}_{\mathrm{Zn}-\mathrm{P}}$ & $\mathrm{A}_{\mathrm{Ga}-\mathrm{Se}}$ & $\mathrm{B}_{\mathrm{Ga}-\mathrm{Se}}$ & $\mathrm{A}_{\mathrm{Ga}-\mathrm{P}}$ & $\mathrm{B}_{\mathrm{Ga}-\mathrm{P}}$ \\
\hline 75.05 & -1.15 & 45.66 & -0.699 & -57.02 & 12.23 & 75.96 & -0.533 \\
\hline
\end{tabular}

Table 6. LVMs calculation for $\mathrm{ZnSe}: \mathrm{P}, \mathrm{Ga}$ using molecular model in $C_{3 \mathrm{~V}}$ symmetry.

\begin{tabular}{|c|c|c|c|c|c|c|c|c|}
\hline \multirow[b]{2}{*}{ Sl. no. } & \multirow{2}{*}{$\begin{array}{l}\text { Calculated } \\
\text { LVMs } \\
\left(\mathrm{cm}^{-1}\right)\end{array}$} & \multicolumn{6}{|c|}{ Displacements } & \multirow{2}{*}{$\begin{array}{c}\text { Experimental } \\
\mathrm{LVMs}^{-1} \\
\left(\mathrm{~cm}^{-1}\right)\end{array}$} \\
\hline & & $x_{1}$ & $y_{1}$ & $z_{1}$ & $x_{2}$ & $y_{2}$ & $z_{2}$ & \\
\hline 1 & $446 \cdot 56$ & $0 \cdot 48$ & $0 \cdot 48$ & $0 \cdot 48$ & $-0 \cdot 31$ & $-0 \cdot 31$ & $-0 \cdot 31$ & 375 \\
\hline 2 & $222 \cdot 45$ & 0.036 & 0.036 & 0.036 & $0 \cdot 17$ & $0 \cdot 17$ & $0 \cdot 17$ & 220 \\
\hline
\end{tabular}

Table 7. Parameters used to evaluate the Green's function for ZnSe.

\begin{tabular}{|c|c|c|c|}
\hline \multirow{2}{*}{$\begin{array}{l}\text { Parameters } \\
\left(\times 10^{4} \text { dyn }[\mathrm{cm}]\right)\end{array}$} & \multicolumn{3}{|c|}{ Phonon frequency $(\omega) \times 10^{14}$ rads } \\
\hline & Type & Experimental & Calculated \\
\hline$A=-2.71$ & $\mathrm{LO}(\Gamma)$ & 0.476 & 0.476 \\
\hline $\mathrm{B}=-1 \cdot 12$ & $\mathrm{TO}(\Gamma)$ & $0 \cdot 401$ & $0 \cdot 401$ \\
\hline$C_{1}=-0 \cdot 38$ & $\mathrm{LO}(\mathrm{L})$ & $0 \cdot 471$ & $0 \cdot 468$ \\
\hline $\mathrm{D}_{1}=0.44$ & TO (L) & 0.414 & $0 \cdot 397$ \\
\hline $\mathrm{E}_{1}=0.00$ & $\mathrm{LO}(\mathrm{X})$ & 0.414 & 0.411 \\
\hline$F_{1}=0.46$ & TO $(\mathrm{X})$ & $0 \cdot 424$ & $0 \cdot 414$ \\
\hline$C_{2}=-0 \cdot 28$ & & & \\
\hline$D_{2}=-0 \cdot 8$ & & & \\
\hline$E_{2}=0 \cdot 00$ & & & \\
\hline$F_{2}=-1 \cdot 23$ & & & \\
\hline
\end{tabular}

$$
T_{2}=\left[\begin{array}{ccc}
\frac{16 \varepsilon M \omega^{2}-100 \Delta \mathrm{A}}{20} & \frac{-4 \varepsilon M \omega^{2}}{10} & \frac{40 \Delta \mathrm{A}}{12 \cdot 65} \\
\frac{\varepsilon M \omega^{2}}{5} & 0 \\
& & -\Delta \mathrm{A}-\Delta \mathrm{B}
\end{array}\right],
$$

(only the upper half of the blocks are given as all the matrices are symmetric). $\Delta \mathrm{A}$ and $\Delta \mathrm{B}$ are change in force constants.

For continuity, to work out the Green's functions for $\mathrm{ZnSe}$, the phonons and eigen displacements should be worked out. This is done in a rigid ion model, taking the central and non central forces into account (Plummelle and Vandevyver 1976). The parameters are refined in a least squares technique and are given in table 7 (With these phonons, the mean square amplitudes of $\mathrm{Zn}$ and $\mathrm{Se}$ are worked out, for comparison with the Green's functions).

The Green's functions are then worked out with the above phonons. To check the correctness of the Green's functions, the mean square amplitude of $\mathrm{ZnSe}$ is cal- culated and compared with the result from the previous experiment and they are $4.148 \AA^{2}$ and $4.57 \AA^{2}$, respectively. The agreement is good. So these green's functions will be used hereafter for defect modes calculation.

To start with, both $\mathrm{A}_{1}$ and $T_{2}$ representations are considered, for $\mathrm{ZnSe}: \mathrm{P}$, having $T_{\mathrm{d}}$ symmetry. The force constants are again from table 1 already given. The defect modes thus calculated are $214 \mathrm{~cm}^{-1}$ and $370 \mathrm{~cm}^{-1}$. Experimental values are $220 \mathrm{~cm}^{-1}$ and $375 \mathrm{~cm}^{-1}$ respectively, for these two representations.

We could see that there are two localized modes $375 \mathrm{~cm}^{-1}$ and $220 \mathrm{~cm}^{-1}$ in these two representations, supporting the information arrived in the molecular model.

But we should see whether this $220 \mathrm{~cm}^{-1}$ is appearing in $C_{3 \mathrm{~V}}$ representation.

As suggested by Nakano et al (1992), first ZnSe : P,Ga is tried in this technique. The same force constants as in table 4 are used for the evaluation of defect modes. But here, no group theoretical simplification is carried out as this is involved with $C_{3 \mathrm{v}}$. So the full $(15 \times 15)$ matrix is used along with the full $\delta l$ matrix to evaluate $|I-g \delta l|$.

The defect modes are identified from where $|I-g \delta l|$ goes to zero. When $\mathrm{ZnSe}: \mathrm{P}, \mathrm{Ga}$ is assumed (for $C_{3 \mathrm{~V}}$ symmetry), the LVM is $229 \mathrm{~cm}^{-1}$ and when $\mathrm{ZnSe}: \mathrm{P}$ with JT distortion is assumed, it is $224 \mathrm{~cm}^{-1}$ and experimental LVMs are 220 and $375 \mathrm{~cm}^{-1}$.

The localized mode $220 \mathrm{~cm}^{-1}$ is again reproduced in this configuration with the allowed degeneracy, whereas $375 \mathrm{~cm}^{-1}$ is seen only in $T_{\mathrm{d}}$ symmetry.

These two investigations reveal that both modes could be identified in $T_{\mathrm{d}}$ symmetry and $220 \mathrm{~cm}^{-1}$ alone in $C_{3 \mathrm{~V}}$ even though in $C_{3 \mathrm{~V}}$ symmetry, an additive impurity $\mathrm{Ga}$ is assumed to occupy one of the $\mathrm{Zn}$ site deliberately.

\section{Discussion}

It is understood from experiments that neutral [Pse] ${ }^{0}$ centres in $\mathrm{ZnSe}: \mathrm{P}$ should have $T_{\mathrm{d}}$ symmetry whereas 
when JT distortion is encountered then [Pse] $]^{-}$may have $C_{3 \mathrm{~V}}$ symmetry, as a result of the three-fold degeneracy in $T_{\mathrm{d}}$ surroundings (Watts et al 1971) leading to a deep centre. The bond length between $\mathrm{P}$ atom and one of the four nearest neighbours $\mathrm{Zn}$ atom is increased by $0.05 \AA$. Nakano et al (1992) from this Raman measurements on ZnSe : P,Ga have shown that there is an LVM $220 \mathrm{~cm}^{-1}$ appearing in this configuration, which has $C_{3 \mathrm{~V}}$ symmetry. Even though from our calculations both by molecular model and Green's functions for $C_{3 \mathrm{~V}}$ symmetry for $\mathrm{ZnSe}: \mathrm{P}, \mathrm{Ga}$ this mode is observed, this is not the aim.

Kwak et al (1994) while studying the LVMs from first principles in $\mathrm{ZnSe}$ : $\mathrm{P}$ observed that one of the $\mathrm{Zn}$ atom will move towards $\mathrm{P}$ thereby reducing the symmetry to $C_{3 \mathrm{~V}}$. Taking this, the LVMs are worked out in the modified configuration of $\mathrm{ZnSe}: \mathrm{P}$ atom and parameters. It is interesting to see that this $220 \mathrm{~cm}^{-1}$ appears here with the required degeneracy.

So, this present investigation predicts that $\mathrm{ZnSe}: \mathrm{P}$ can have $C_{3 \mathrm{~V}}$ symmetry (to explain the LVM $220 \mathrm{~cm}^{-1}$ ) provided JT distortion is taken into account. Since $\mathrm{P}$ is amphoteric impurity in $\mathrm{ZnSe}$, the other possibility of $\mathrm{P}$ substituting $\mathrm{Zn}$ site is also considered for the present calculations. It is found out again that the $220 \mathrm{~cm}^{-1}$ is appearing in the $\mathrm{A}_{1}$ representation of $C_{3 \mathrm{~V}}$ symmetry arising due to $\mathrm{JT}$ distortion.

In conclusion, it is to be mentioned that $\mathrm{ZnSe}: \mathrm{P}$ can have $C_{3 \mathrm{~V}}$ where $\mathrm{JT}$ distortion is assumed with about $\sim 0 \cdot 2 \AA$ of relaxation of one of the atom towards $P$.

Further work is going on to see whether an interstitial defect will also have $C_{3 \mathrm{~V}}$ symmetry, by working out the LVMs.

\section{Acknowledgement}

The authors thank the Council of Scientific and Industrial Research, New Delhi, for financial assistance.

\section{References}

Hasse M A, Qiu J, Depuydt J M and Cheng H 1991 Appl. Phys. Lett. 591272

Jandl S, Brebner J L and Powell P M 1976 Phys. Rev. B13 686

Kusakov V I, Rusakov A P and Menster A N 1973 Sov. Phys.Solid State 141869

Kwak K W, Vanderbilt D and King Smith R D 1994 Phys. Rev. B50 2711

Maradudin A A, Montroll E W, Weiss G H and Ipatova I P 1971 Theory of lattice dynamics in the harmonic approximation (New York: Academic Press) 2nd ed.

Matsuo H, Kagaya H M and Soma T 1984 Phys. Status Solidi(b) $\mathbf{1 2 4} 37$

Nakano K, Boyce P J, Davies J J and Wolverson D $1992 \mathrm{~J}$. Cryst. Growth 117331

Nicholls J E and Davies J J 1979 J. Phys. C 121917

Plummelle P and Vandevyver M 1976 Phys. Status Solidi(b) 73 271

Qiu J, Depuydt J M and Cheng H 1991 Appl. Phys. Lett. 59 2992

Sheleg A U and Kutas A A 1981 Sov. Phys. Solid State 231448

Taylor W 1967 Phys. Letts A24 556

Watts R K, Holton W C and Witt M D 1971 Phys. Rev. B3 404

Wolk J A, Kruger M B, Heyman J N, Walukiewiez W, Jeanloz R and Haller E E 1991 Phys. Rev. Lett. 66774

Yao T and Okada K 1986 Jap. J. Appl. Phys. 25821 